\title{
Anti-urolithic, anti-inflammatory and anti- bacterial properties of various extracts from Musa balbisiana Colla fruits
}

\author{
Hai Trieu Ly ${ }^{1}$, \\ Van Minh Le ${ }^{1}$, \\ Minh Thu Nguyen ${ }^{1}$, \\ Thanh Huyen Pham², \\ Hoang Dung Nguyen ${ }^{3}$, \\ Minh Khoi Nguyen ${ }^{2 *}$ \\ 1 Research Center of Ginseng and Medicinal \\ Materials (CGMM), National Institute of \\ Medicinal Materials, Ho Chi Minh City, \\ Vietnam \\ 2 National Institute of Medicinal Materials \\ (NIMM), Hanoi, Vietnam \\ 3 Institute of Tropical Biology, VAST, Ho \\ Chi Minh City, Vietnam
}

*Corresponding author:

Minh Khoi Nguyen

khoinm@nimm.org.vn

Keywords:

Musa balbisiana fruits, Extract and fractions, Urolithiasis, Biological activities.

Pharmaceutical Sciences Asia @ 2021 by Faculty of Pharmacy, Mahidol University, Thailand is licensed under CCBY-NC-ND 4.0. To view a copy of this license, visit https:// www.creativecommons.org/ licenses/by-nc-nd/4.0/

\begin{abstract}
Musa balbisiana fruits is an important and commonly used plant for its medicinal and pharmacological properties. Urolithiasis has become a very common clinical disease in over the world. The present study aimed to evaluate in vitro anti-urolithic, antiinflammatory, and antibacterial activities of crude and fractionated extracts of M. balbisiana fruits. The M. balbisiana fruit extracts were evaluated anti-urolithic property by nucleation and aggregation assays of calcium oxalate crystallization, anti-inflammatory activity by protein denaturation assay and red blood cell membrane stabilization, and antibacterial activity using the well diffusion agar method, minimum inhibitory concentration assay, and minimum bactericidal concentration assay. Results indicated that crude extract and different fractions had anti-urolithic, antibacterial, and anti-inflammatory activities. Chloroform fraction had the highest ability against calcium oxalate crystals formation with an $\mathrm{IC}_{50}$ value of $22.04 \pm 1.09 \mu \mathrm{g} / \mathrm{mL}$, which was comparable with sodium citrate $(202.08 \pm 18.46 \mu \mathrm{g} / \mathrm{mL})$. In the active in against crystals aggregation, $n$-hexane fraction had the highest activity with an $\mathrm{IC}_{50}$ value of $414.77 \pm 10.85 \mu \mathrm{g} / \mathrm{mL}$, whereas $\mathrm{IC}_{50}$ value of sodium citrate was $1390.33 \pm 92.66 \mu \mathrm{g} / \mathrm{mL}$. Furthermore, crude and fractionated extracts presented anti-inflammatory activity through inhibition protein denaturation and red blood cells membrane stabilization. Simultaneously, the crude extract and different fractions exhibited the ability to against E. coli, $P$. aeruginosa, and $S$. aureus. Taken together, the present study had demonstrated that M. balbisiana fruits has properties that support urolithiasis disease.
\end{abstract}

\section{INTRODUCTION}

In this day and age, urolithiasis has become a very common clinical disease in the appearance of more and more cases of kidney stone victims in over the world. Based on the rate of occurrence, the majority of kidney stones are typically calcium-containing stones, especially calcium oxalate, with the rates of more than $80 \%$ cases as the monohydrate or dihydrate forms ${ }^{1}$. Three stages are complicated in the formation of the crystals through nucleation, growth, and aggregation processes. The stone formation begins as the occurrence of one or more calculi in any location inside the urinary tract and the formation of these nuclei is from supersaturated urine ${ }^{2}$. There are many different factors affect the supersaturation of urine, 
consist of ionic strength, urinary $\mathrm{pH}$, and solute concentration of certain glycoproteins, complexations, and some pathogenic factors ${ }^{3}$. It is evaluated that $12 \%$ of the population in industrialized countries encounter urinary stone disease with a different recurrences rate between males and females with $70-80 \%$ and $47-60 \%$ cases, respectively ${ }^{4,5}$. The etiology of this illness is identified based on geography, genetics, diet, and low physical activities. The temperature rises worldwide because of the impacts of global warming, it has been anticipated that there could be an expansion of 1.6-2.2 million lifetime instances of kidney stone by $2050^{6}$. Vietnam is the nation located in the stone-forming belt (the incidence of urolithiasis is high). In Vietnam, urolithiasis is found to be the case in $40-60 \%$ of all general surgery cases in the department of urology. Urolithiasis is a multifactorial disease wherein stones are formed at different locations within the urinary tract. Kidney stones may cause injury in the urinary tract and obstruction of the urine stream. Besides that, urinary tract infections may occur as a result of complications that existent before or after a urolithiasis treatment ${ }^{7}$. Although the disease does not cause life-threatening, patients will suffer from burning sensation and discomfort. Moreover, calcium oxalate $\left(\mathrm{CaO}_{\mathrm{x}}\right)$ also know as non-infectious crystals deposition relatively common presence in the urinary tracts and is frequently relative to inflammation and damage for cells. Injury and inflammation can influence to cell membrane due to a large amount of phosphatidylserine, which in turn rises $\mathrm{CaO}_{x}$ crystals binding by kidney epithelial cells ${ }^{8}$. Furthermore, urolithiasis is a favorable factor for the formation and development of urinary tract infections. In particular, the majority of cases are caused by the Escherichia coli bacteria (about $90 \%$ of cases are caused by $E$. coli bacteria) because this bacterium is able to penetrate directly into the urinary tract or endoscopic surgery, in addition to E. coli, there are also bacteria such as Staphylococcus, Pseudomonas, Klebsiella, and Proteus ${ }^{9}$. It is important that recurrence is common ${ }^{10}$. Therefore, resistance to these bacterial strains can alleviate or prevent urinary tract infections.

There are some ways to treatment and management of renal stones can be removed or broken to small pieces such as drugs, traditional surgery or surgery with shock wave lithotripsy. However, the complex and expensive method cannot completely wash out the stones. Besides, the injury impact of shock waves, retained remainder stone fragments and the potent of infection may cause acute renal injury, a reduction in renal function and a raise in stone recurrence ${ }^{11}$. Otherwise, using medication follow the prescription is effective in reducing inflammation and the risk of recurrent pain, especially, the active presence for stone elimination quickly. However, there are not effective in all patients as well as many of side effects that compromise their long terms use due to the large amount of excipients are presented in synthesis medication. Therefore, the use of herbs in the development of supplements and alternative drugs in the treatment of human diseases continues to expand rapidly across the world. The purposes in anti-urolithic activity of plants or herbal formulation are crystallization inhibition or recurrence of stones along with anti-inflammatory and antibacterial activity. World Health Organization estimates that over $60 \%$ of the global population and around $80 \%$ in developing countries use traditional and medicinal plants for primary healthcare and treatment purposes ${ }^{12}$. Currently, there is renewed interest in medicinal plants in the prevention and cure of urolithiasis due to their traditional acceptability, low toxicity, and absence of side effects ${ }^{13}$.

Musa balbisiana Colla, is a robust herb, commonly known as wild species of banana belonging to the family Musaceae. Over the last several decades, the health benefits of $M$. balbisiana have devoted considerable attention, which are traditionally used to treat communicable as well as noncommunicable diseases ${ }^{14,15}$. All parts of $M$. balbisiana are used as traditinal medicine to cure several diseases such as its flowers are being used in bronchitis, dysentery, and on ulcers ${ }^{16}$; boiled flowers are given for the diabetes and jaundice treatments ${ }^{16,17}$; the astringent plant sap is used for the cases of hysteria, epilepsy, leprosy, and fevers ${ }^{16}$. It has been known for many pharmacological activities, like antioxidant, anti-inflammatory, antidiabetic and antibacterial ${ }^{14,16}$. In Vietnam, M. balbisiana is a popular plant due to easy cultivation as well as high tolerance in many areas. Moreover, this plant is familiar to live with low price but high vitamins and minerals. M. balbisiana fruits have been used as the clinical treatment for treating diabetes by pressing banana juice, urolithiasis by simmering unripened fruits and reducing stress by eating ripened fruits. Therefore, the component of $M$. balbisiana is useful to treat in various ailments. Some previous reports showed that the presence of various bioactive phytochemicals 
consists of flavonoids, polyphenols, tannins, monoterpenoids, sesquiterpenoids, quinones, and saponins in $M$. balbisiana fruits ${ }^{18}$. The previous researches showed that saponins and flavonoids were the potential compounds for treating kidney stone disease ${ }^{19,20}$. However, there have been no reports regarding the evaluation of $M$. balbisiana fruit extracts based on antiurolithic activity. In the present study, $\mathrm{CaO}_{x}$ crystals are cultured in the artificial technique. The effect of crude and fractionated extract of M. balbisiana is studied on the inhibition and aggregation of $\mathrm{CaO}_{x}$ crystals. In crystallization study kinetic and thermodynamic are specific conditions of formation and aggregation of crystalline species. Besides, evaluation of the biological activities of crude and fractionated extract of $M$. balbisiana fruits in anti-bacteria, and anti-inflammation, which are relevant factors to kidney stone disease.

\section{MATERIALS AND METHODS}

\subsection{Plant materials}

M. balbisiana fruits (Fresh green banana including peel, flesh, and seeds) were collected on May 2019 from Tan Thanh District, Long An Province. The plant samples were identified and authenticated by Le Duc Thanh (Research Center of Ginseng and Medicinal Materials, Ho Chi Minh City) and a voucher specimen (TNDLQCH-2019) was deposited for M. balbisiana Colla. The dried samples were ground to a fine powder and stored individually in airtight PVE bag at the Research Center of Ginseng and Medicinal Materials in Ho Chi Minh City (Sample code: QCH-TTS-2019).

\subsection{Chemicals and reagents}

Chemicals and reagents: Ethanol (OPC Pharmaceutical Company); $n$-hexane, chloroform, ethyl acetate, $n$-butanol (VN-Chemsol, Co. Ltd); egg albumin (HIMEDIA); calcium chloride, sodium oxalate, sodium citrate, sodium chloride, Tris-HCl, yeast extract, peptone, diclofenac sodium, and amoxicillin were purchased from Sigma-Aldrich ${ }^{\circledR}$ Co. Ltd. Besides, the bacterial strains used in this study were Escherichia coli (E. coli) (ATCC $\left.{ }^{\circledR} 25922\right)$, Pseudomonas aeruginosa (P. aeruginosa) (ATCC ${ }^{\circledR}$ 27853) and Staphylococcus aureus (S. aureus) (ATCC $\left.{ }^{\circledR} 29213\right)$.

\subsection{Extraction and fractionation}

The dried powdered material was extracted (The ratio of dried material: solvent is 1: $20(\mathrm{~g} / \mathrm{mL}))$ with $45 \%$ ethanol by hot extraction method during 60 minutes to obtain hydroethanolic crude extract (CE extract). The above crude extract was collected via filtering and then concentration using a rotary evaporator at $70{ }^{\circ} \mathrm{C}$ under reduced pressure. Using liquid-liquid extract to get fractionated extracts, the potential crude extract was solubilized in distilled water and sequentially extracted with solvents of increasing polarity ( $n$-hexane, chloroform, ethyl acetate, and $n$-butanol). The fractionated extracts including $n$ hexane (F1), chloroform (F2), ethyl acetate (F3), $n$-butanol (F4), and aqueous (F5) fractions. The crude and fractionated extracts were stored at 2-8 ${ }^{\circ} \mathrm{C}$ and dissolved in a suitable solvent to yield a stock solution.

The extraction yield of crude extract was estimated using the expression:

$$
\mathrm{H}(\%)=([\mathrm{m} \times(1-\mathrm{a})] /[\mathrm{M} \times(1-\mathrm{A})]) \times 100
$$

In which, $\mathrm{H}$ is extraction yield (\%), $\mathrm{m}$ is mass of the crude extract $(\mathrm{g}), \mathrm{M}$ is mass of the dried powder $(\mathrm{g})$, a is moisture of the crude extract $(\%)$, and $\mathrm{A}$ is moisture of the dried powder (\%).

The extraction yield of fractionated extracts was estimated using the expression:

$$
\mathrm{H}(\%)=(\mathrm{m} /[\mathrm{M} \times(1-\mathrm{A})]) \times 100
$$

In which, $\mathrm{H}$ is extraction yield (\%), $\mathrm{m}$ is mass of the fractionated extract $(\mathrm{g}), \mathrm{M}$ is mass of the crude extract $(\mathrm{g})$, and $\mathrm{A}$ is moisture of the crude extract $(\%)$.

\subsection{In vitro anti-urolithic activity}

\subsubsection{Nucleation assay}

The in vitro anti-urolithic activity of crude and fractionated extracts was carried out by nucleation assay on calcium oxalate $\left(\mathrm{CaO}_{\mathrm{x}}\right)$ crystal formation according to a previously described method with minor modification ${ }^{21}$. Calcium chloride $\left(\mathrm{CaCl}_{2}\right)(5 \mathrm{mmol} / \mathrm{L})$ and sodium oxalate $\left(\mathrm{Na}_{2} \mathrm{C}_{2} \mathrm{O}_{4}\right)$ solution $(7.5 \mathrm{mmol} / \mathrm{L})$ were prepared in Tris- $\mathrm{HCl}(0.05 \mathrm{~mol} / \mathrm{L})$ and $\mathrm{NaCl}(0.15$ $\mathrm{mol} / \mathrm{L})$ buffer $(\mathrm{pH}=6.5)$. Briefly, $250 \mu \mathrm{L}$ of each crude or fractionated extract or sodium citrate (positive control) at different concentrations was mixed with $750 \mu \mathrm{L} \mathrm{CaCl}_{2}$ solution. Crystallization was started by adding $750 \mu \mathrm{L}$ of $\mathrm{Na}_{2} \mathrm{C}_{2} \mathrm{O}_{4}$ solution. Then, final mixtures were incubated for 30 mins at $37{ }^{\circ} \mathrm{C}$ and the absorbance was measured at $620 \mathrm{~nm}$. In the case of a control experiment, $250 \mu \mathrm{L}$ of the buffer was added to the calcium chloride solution. The measurements 
were performed in triplicate, and the $\mathrm{IC}_{50}$ values (the concentration of sample that results in 50\% inhibition of maximal activity) were determined.

Percentage inhibition of calcium oxalate crystals formation was estimated using the expression:

$\%$ Inhibition $=\left[\left(A b s_{\text {control }}-A b s_{\text {sample }}\right) / A b s_{\text {control }}\right] \times 100$

In which, $A b s_{\text {control }}$ is the absorbance of the blank without test extract and $A b s_{\text {sample }}$ is the absorbance of the sample with test extract.

Microscopic evaluation number, size, and morphology of $\mathrm{CaO}_{x}$ crystals formed in absence or presence of crude and fractionated extracts as well as sodium citrate were overally determined using a Leica DM 2500 LED microscope at $400 \times$ magnification.

\subsubsection{Aggregation assay}

The in vitro anti-urolithic activity of crude and fractionated extracts was carried out by aggregation assay on calcium oxalate monohydrate crystal clusters according to a previously described method with minor modification ${ }^{21}$. Calcium chloride $\left(\mathrm{CaCl}_{2}\right) \quad(50 \mathrm{mmol} / \mathrm{L})$ and sodium oxalate $\left(\mathrm{Na}_{2} \mathrm{C}_{2} \mathrm{O}_{4}\right)$ solutions $(50 \mathrm{mmol} / \mathrm{L})$ were prepare in Tris- $\mathrm{HCl}(0.05 \mathrm{~mol} / \mathrm{L})$ and $\mathrm{NaCl}$ $(0.15 \mathrm{~mol} / \mathrm{L})$ buffer $(\mathrm{pH}=6.5)$, then mixed together, heated to $60{ }^{\circ} \mathrm{C}$ in a water bath for $1 \mathrm{hr}$ and then incubated overnight at $37{ }^{\circ} \mathrm{C}$ to prepare seed $\mathrm{CaO}_{\mathrm{x}}$ crystals. After drying, $\mathrm{CaO}_{\mathrm{x}}$ crystal solution $(5 \mathrm{mg} / \mathrm{mL})$ was prepared in buffer $(\mathrm{pH}=6.5) .1 \mathrm{~mL}$ of herb extracts at different concentrations were added to $3 \mathrm{~mL} \mathrm{CaO}_{\mathrm{x}}$ solution, the mixture was vortexed and then incubated at $37{ }^{\circ} \mathrm{C}$ for 30 minutes. Optimal density of the final mixtures was then measured at $620 \mathrm{~nm}$ wavelength. Percentage inhibition of calcium oxalate crystals aggregation was estimated using the expression: $\%$ Inhibition $=\left[\left(A b s_{\text {control }}-A b s_{\text {sample }}\right) / A b s_{\text {control }}\right] \times 100$ In which, $A b s_{\text {control }}$ is the absorbance of the blank without test extract and $A b s_{\text {sample }}$ is the absorbance of the sample with test extract.

\subsection{In vitro anti-inflammatory activity}

\subsubsection{Protein denaturation assay}

Anti-inflammatory activity of crude and fractionated extracts of $M$. balbisiana fruits were determined by protein denaturation method according to the method previously described with minor modifications ${ }^{22}$. Briefly, $2 \mathrm{~mL}$ of varying concentrations of extract or standard diclofenac sodium was mixed with $2.9 \mathrm{~mL}$ of phosphate buffered saline $(\mathrm{pH}=6.4)$. Then, 0.1 $\mathrm{mL}$ of egg albumin was added and incubate further at $(37 \pm 1){ }^{\circ} \mathrm{C}$ for 15 minutes. Denaturation was established by keeping the reaction mixture at $70{ }^{\circ} \mathrm{C}$ in a water bath for 10 minutes. After cooling, the absorbance readings were recorded at $660 \mathrm{~nm}$. Diclofenac sodium (Sigma Co. Ltd, USA), a powerful non-steroidal anti-inflammatory drug were used as a positive control. The measurements were performed in triplicate and the average is taken. The $\mathrm{IC}_{50}$ value (the concentration of sample that results in 50\% inhibition of maximal activity) were determined.

Percentage of protein denaturation inhibition was estimated using the expression:

$\%$ Inhibition $=\left[\left(A b_{\text {control }}-A b s_{\text {sample }}\right) / A b_{\text {control }}\right] \times 100$

In which, $A b s_{\text {control }}$ is the absorbance of the blank without test extract and $A b s_{\text {sample }}$ is the absorbance of the sample with test extract.

\subsubsection{Membrane stabilization} suspension

Preparation of red blood cells (RBCs)

The blood was collected from healthy mice and transfered to the centrifuge tubes. The tubes were centrifuged at $3000 \mathrm{rpm}$ for 10 minutes and were washed three times with sodium phosphate buffer $(\mathrm{pH}=7.4)$, containing normal saline $154 \mathrm{mM}$ by centrifuge. The volume of blood was measured and reconstituted as a $10 \%$ $(v / v)$ suspension with isotonic buffer solution ${ }^{22}$.

\section{Heat-induced hemolysis}

Anti-inflammatory activity of crude and fractionated extracts of M. balbisiana fruits were determined by heat-induced hemolysis according to the method previously described with minor modifications ${ }^{22}$. The reaction mixture consists of $1 \mathrm{~mL}$ test sample of different concentrations and $1 \mathrm{~mL}$ of $10 \%$ RBCs suspension, instead of the test sample only saline was added to the control test tube. All the centrifuge tubes containing reaction mixture were incubated in a water bath at $56{ }^{\circ} \mathrm{C}$ for 30 minutes. At the end of the incubation, the tubes were cooled under running tap water. The reaction mixture was centrifuged at $2500 \mathrm{rpm}$ for 10 minutes and the absorbance of the supernatants was taken at $560 \mathrm{~nm}$. Diclofenac sodium was used as a positive control. The experiment was performed in triplicates for all the test samples.

\section{Hypotonicity-induced hemolysis}


Anti-inflammatory activity of crude and fractionated extracts of $M$. balbisiana fruits were determined by hypotonicity-induced hemolysis according to the method previously described with minor modifications ${ }^{23} .5 \mathrm{~mL}$ of sample extracts with different concentration were separately mixed with $1 \mathrm{~mL}$ of phosphate buffer, $2 \mathrm{~mL}$ of hyposaline and $0.5 \mathrm{~mL}$ of RBCs suspension. All the assay mixtures were incubated at $37{ }^{\circ} \mathrm{C}$ for 30 minutes and centrifuged at 3000 rpm for 20 minutes. The supernatant liquid was decanted and the hemoglobin content was estimated by a spectrophotometer at $560 \mathrm{~nm}$. Diclofenac sodium was used as a positive control. The experiment was performed in triplicates for all the test samples.

The percentage inhibition of hemolysis was estimated using the expression:

$\%$ Inhibition $=\left[\left(A b s_{\text {control }}-A b s_{\text {sample }}\right) / A b s_{\text {control }}\right] \times 100$

In which, $A b s_{\text {control }}$ is the absorbance of the blank without test extract and $A b s_{\text {sample }}$ is the absorbance of the sample with test extract.

\subsection{Antibacterial activity}

\subsubsection{Determination of zone of inhibition method}

The in vitro anti-bacterial activity of crude extracts of $M$. balbisiana fruits were carried out by determination of zone of inhibition according to a previously described method with minor modification ${ }^{24}$. Bacterial cultures grown overnight were adjusted to a density of $1 \times 10^{6}$ $1 \times 10^{8} \mathrm{CFU} / \mathrm{mL}$, which were spread evenly onto Luria-Bertani agar plates using sterile stick. Agar wells ( $D_{\text {agar well }}: 6 \mathrm{~mm}$ in diameter) were made using punching tool. Test sample $(100 \mu \mathrm{L})$ at various concentrations were added to each well. The plates were incubated at $37{ }^{\circ} \mathrm{C}$ for 24 hr. The diffusion of the extract into the agar media inhibited the growth of the bacteria that formed zone of inhibition around the agar well. Determined the diameter of the zone of inhibition (D: $\mathrm{mm})$ according to the formula: $\mathrm{D}=\left(D_{\text {test sample }}\right.$ - $\left.D_{\text {agar well }}\right)-\left(D_{\text {negative control }}-D_{\text {agar well }}\right)$. Amoxicillin and $10 \%(\mathrm{v} / \mathrm{v})$, solvent dilluted extracts (Merck $\mathrm{KgaA}$ ) were used as a positive and negative control, respectively. All experiments were run in duplicate and were repeated at least three times.

\subsubsection{Quantitative antibacterial activity assay by $M I C$ and $M B C$}

The in vitro anti-bacterial activity of crude extracts of $M$. balbisiana fruits were carried out by determination minimum inhibitory concentration (MIC) and minimal bactericidal concentration (MBC) according to a previously described method with minor modification ${ }^{24}$. $E$. coli, $P$. aeruginosa, and $S$. aureus were used to study. The MIC and MBC value of the extract was determined as the lowest concentrations that completely inhibited and killed respectively bacterial growth after 24 hours of incubation at $37^{\circ} \mathrm{C}$. The extract was diluted in suitable culture media to $1 / 2$ dilution in the plate. Added $1 \mu \mathrm{L}$ of bacterial suspension to be cultured for 24 hours at $37{ }^{\circ} \mathrm{C}$ to a density of approximately $1 \times 10^{6}-$ $1 \times 10^{8} \mathrm{CFU} / \mathrm{mL}$ to the surface of the agar plate. The agar plates were incubated at $37{ }^{\circ} \mathrm{C}$ and observed counts of colonies growing on agar plates after 24 hours. All experiments were run in duplicate and repeat at least three times. Amoxicillin (Merck KgaA) and solvent dilluted extracts were used as a positive and negative control, respectively. The MIC was the lowest concentration of antimicrobial agents inhibiting the growth of the pathogen and the MBC was the lowest concentration almost killing the initial bacterial population. The MIC and MBC were observed for the presence or absence of bacterial growth after incubation.

\subsection{Data analysis}

The results were expressed in terms of mean \pm SEM (Standard error of the mean) using MS Excel 2016 software. IC $_{50}$ values in the assays were determined based on the equation showing the correlation between concentration and percentage inhibition using Graphpad Prism software (version 8, Inc., La Jolla, CA, USA). Data were analyzed by GraphPad Prism software using t-test.

\section{RESULTS}

\subsection{Extraction yield of crude and fractionated extracts}

The dried powdered material and crude extract were determined loss on drying (LOD) according to regulations in Vietnam Pharma copoeia $5^{\text {th }}$ Edition. Result showed that the LOD of the dried powder and crude extract were 11.44 $\pm 0.24 \%$ and $13.68 \pm 0.21 \%$, respectively, which reached the standard about the raw material $(\leq 13 \%)$ and condensed extract $(\leq 20 \%)$. The yield of crude and fractionated extracts of $M$. balbisiana fruits was presented in Figure. 1. 


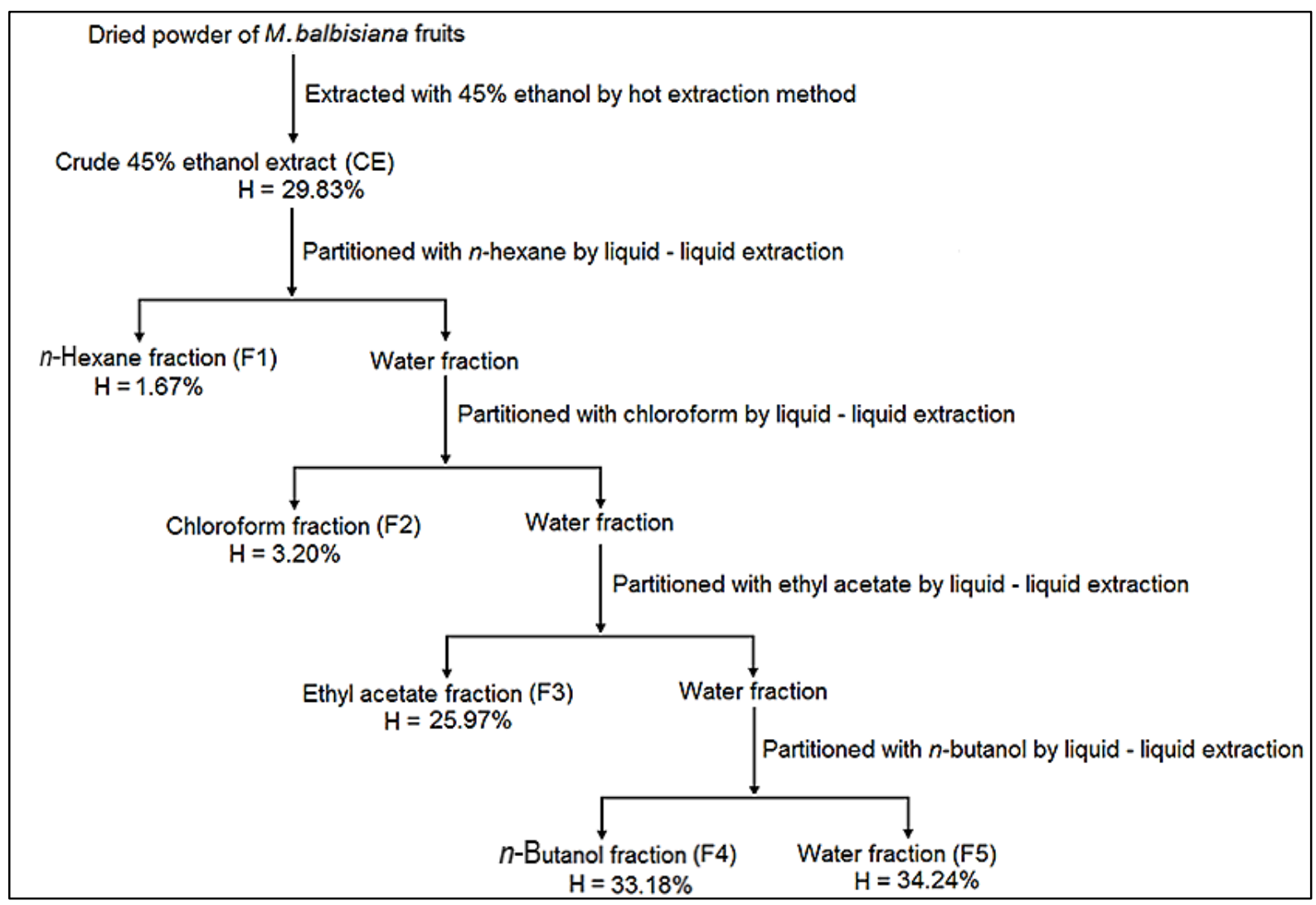

Figure 1. Procedures of extraction and fractionation of M. balbisiana fruits.

\subsection{In vitro anti-urolithic activity of crude and fractionated extracts}

The effect of the crude and fractionated extracts of M. balbisiana fruits on the nucleation of calcium oxalate crystals was determined by the percentage of inhibition under standard conditions at extract concentrations of 100-1000 $\mu \mathrm{g} / \mathrm{mL}$. The results in Figure 2A showed that all tested extracts were able to control crystal formation, which were a steep increase in inhibitory activity with increasing concentration of these extracts. Interestingly, chloroform fraction showed significantly greater in anti-nucleation activity compared to other extracts at its highest concentration $(800 \mu \mathrm{g} / \mathrm{mL})$. Otherwise, the percentage inhibition at the highest concentration $(1000 \mu \mathrm{g} / \mathrm{mL})$ of the $n$-hexane fraction also performed higher than the crude extract, ethyl acetate, and $n$-butanol fractions. Figure 2B displayed the $\mathrm{IC}_{50}$ value of the crude extract and its fractions, compared with sodium citrate. In which, chloroform fraction was indicated the lower $\mathrm{IC}_{50}$ value compared to positive control, meaning that chloroform fraction was the best potency on inhibitory activity on crystal formation.

Especially, the aqueous fraction controlled the crystallization by promoting the precipitation of calcium oxalate particles, the size and number of crystals were not reduced, but interestingly the shape of crystals as well got changing, the formation of calcium oxalate dihydrate (COD) rather than calcium oxalate monohydrate (COM) crystals. That led to a non-significant decrease in turbidity and data was negative. Therefore, the activity of aqueous fraction in inhibiting the formation of crystals was just observed in pictures. (Figure 3.)

Similarly, in the aggregation assay, the crude and fractionated extracts of $M$. balbisiana fruits were investigated at concentrations of $250-2000 \mu \mathrm{g} / \mathrm{mL}$. These extracts could keep $\mathrm{CaO}_{\mathrm{x}}$ particles dispersed in solution. The results were demonstrated in Figure 2C. Percentage inhibition of $\mathrm{CaO}_{\mathrm{x}}$ crystal aggregation increased in extract dependent manner at varying concentrations. The $n$-hexane fraction also showed greater in against of COM crystal aggregation compared to other extracts while aqueous fraction was negligible attribution on this state. The $\mathrm{IC}_{50}$ value was compared between different extracts with sodium citrate. Sodium citrate also represented inhibitory activity on COM crystal aggregation but was less active than the crude potential extract, $n$-hexane and ethyl acetate fractions. (Figure 2D.)

When finished nucleation experiment 
and tested groups were observed under light microscopy, the crude and fractionated extracts of $M$. balbisiana fruits contained nucleationpreventing agents. In the negative control showed mostly COM formation, but $M$. balbisiana fruit extracts, excepted F5 (aqueous fraction), had the ability to control forming calcium oxalate crystals and break down crystals into smaller at a concentration of $1000 \mu \mathrm{g} / \mathrm{mL}$, whereas F5 at the highest concentration could convert COM to COD crystals, with few COM crystals and more COD crystal, compared with the positive control was fewer COD crystals. (Figure 3.)

\subsection{In vitro anti-inflammatory activity of crude and fractionated extracts}

The crude extract and chloroform, ethyl acetate, $n$-butanol and aqueous fractions of $M$. balbisiana fruits were able to inhibit protein denaturation in a concentration-dependent manner. The inhibitory effect of different extracts at different concentrations $(200-1600 \mu \mathrm{g} / \mathrm{mL})$ on protein denaturation is shown in Figure 4A.

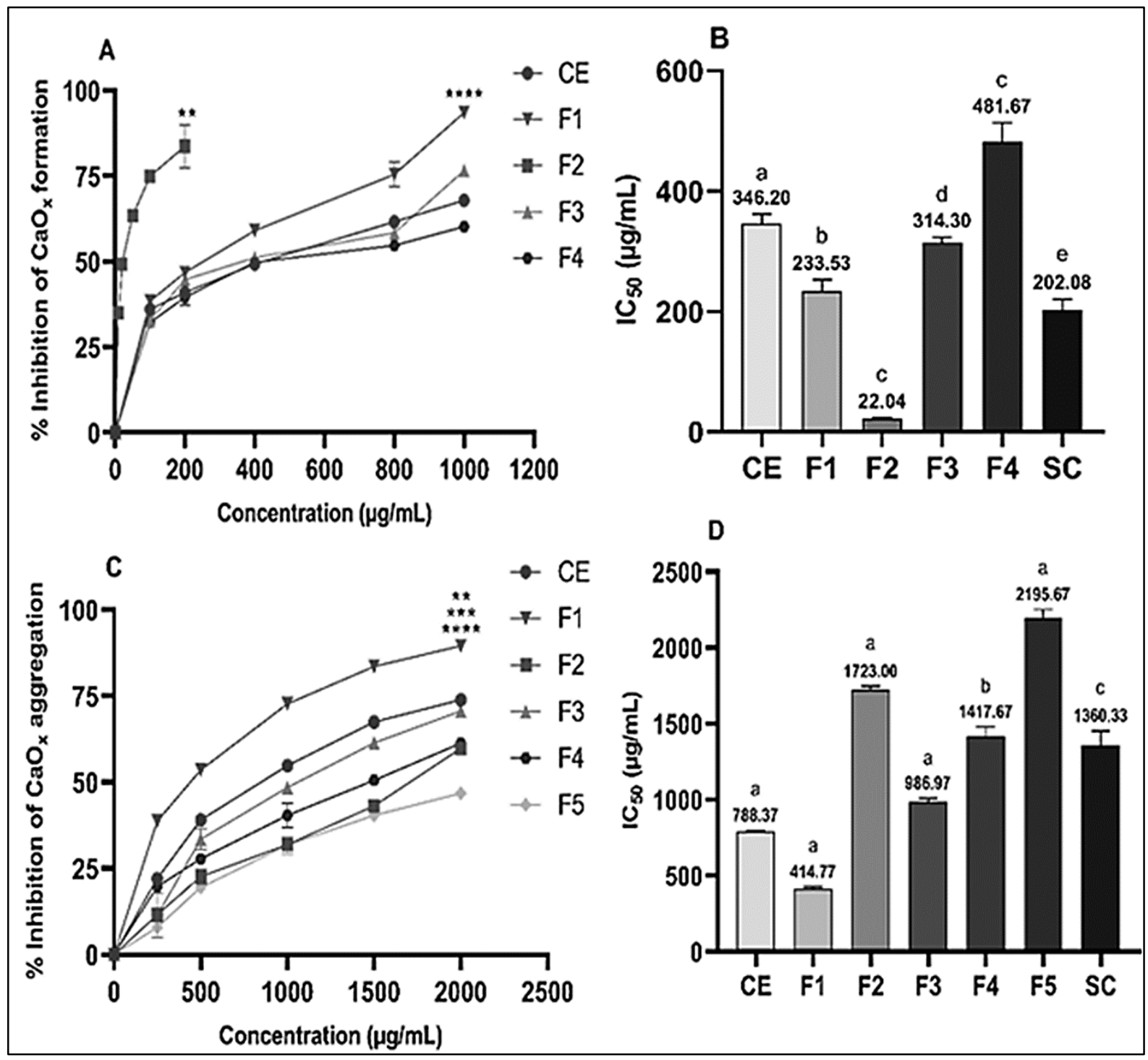

Figure 2. In vitro anti-urolithiatic activities of potential crude and fractionated extracts of $M$. balbisiana fruits on calcium oxalate crystals formation and aggregation. (SC) Sodium citrate, (CE) Crude extract, (F1) $n$-hexane, (F2) chloroform, (F3) ethyl acetate (F4) $n$-butanol, and (F5) aqueous fractions. (A) Percentage inhibition of $\mathrm{CaO}_{\mathrm{x}}$ crystals formation: ${ }^{* *} p<0.01$ and ${ }^{* * * *} p<0.0001$ significant difference compared to other extracts at the same concentration. (B) The $\mathrm{IC}_{50}$ values in nucleation assay: ${ }^{a} p,{ }^{c} p,{ }^{d} p$, and ${ }^{e} p$ significant difference compared to other extracts, excepted F3, SC, CE, and F1, respectively; ${ }^{b} p<0.05$ significant difference compared to all other extracts. (C) Percentage inhibition of $\mathrm{CaOx}$ crystals aggregation: ${ }^{* *} p<0.01$ significant difference compared to CE extract; ${ }^{* * *} p<0.001$ significant difference compared to F2, F3, and F4 fractions; ${ }^{* * * *} p$ $<0.0001$ significant difference compared to F5 fraction. (D) The $\mathrm{IC}_{50}$ values in aggregation assay: ${ }^{a} p<0.05$ significant difference compared to all other extracts; ${ }^{b} p<0.05$ and ${ }^{c} p<0.05$ significant difference compared to other extracts, excepted $\mathrm{SC}$ and F4 fractions, respectively. Values were expressed as Mean $\pm \operatorname{SEM}(n=3)$. 


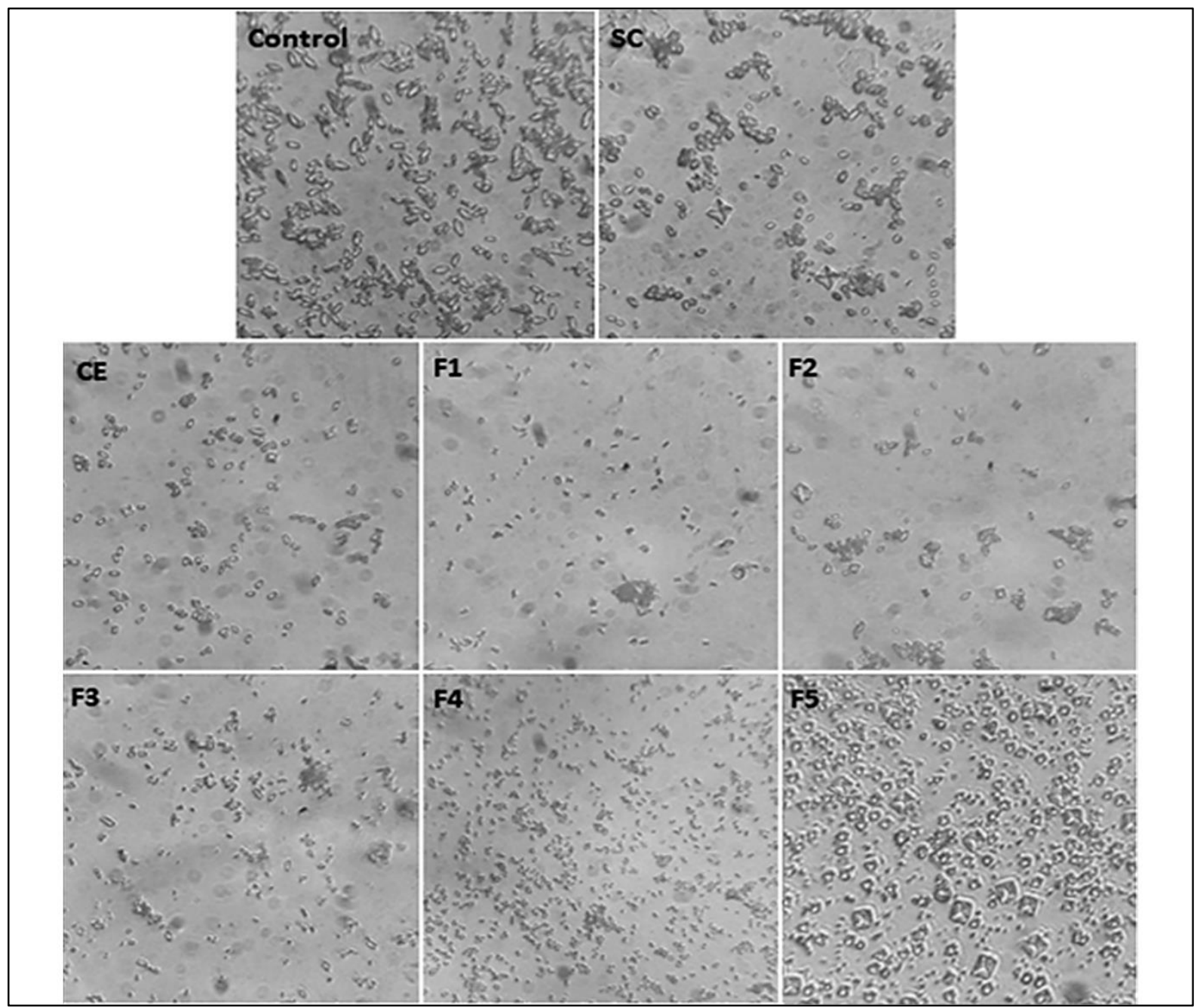

Figure 3. The photomicrograph showing activity of M. balbbisiana fruit extracts on the calcium oxalate crystallization (light microscope 400×); SC, CE, F1, F2, F3, F4, and F5: Sodium citrate, crude extract, $n$-hexane, chloroform, ethyl acetate, $n$ butanol, and aqueous fractions, repectively (at a concentration of $1000 \mu \mathrm{g} / \mathrm{mL}$ ).

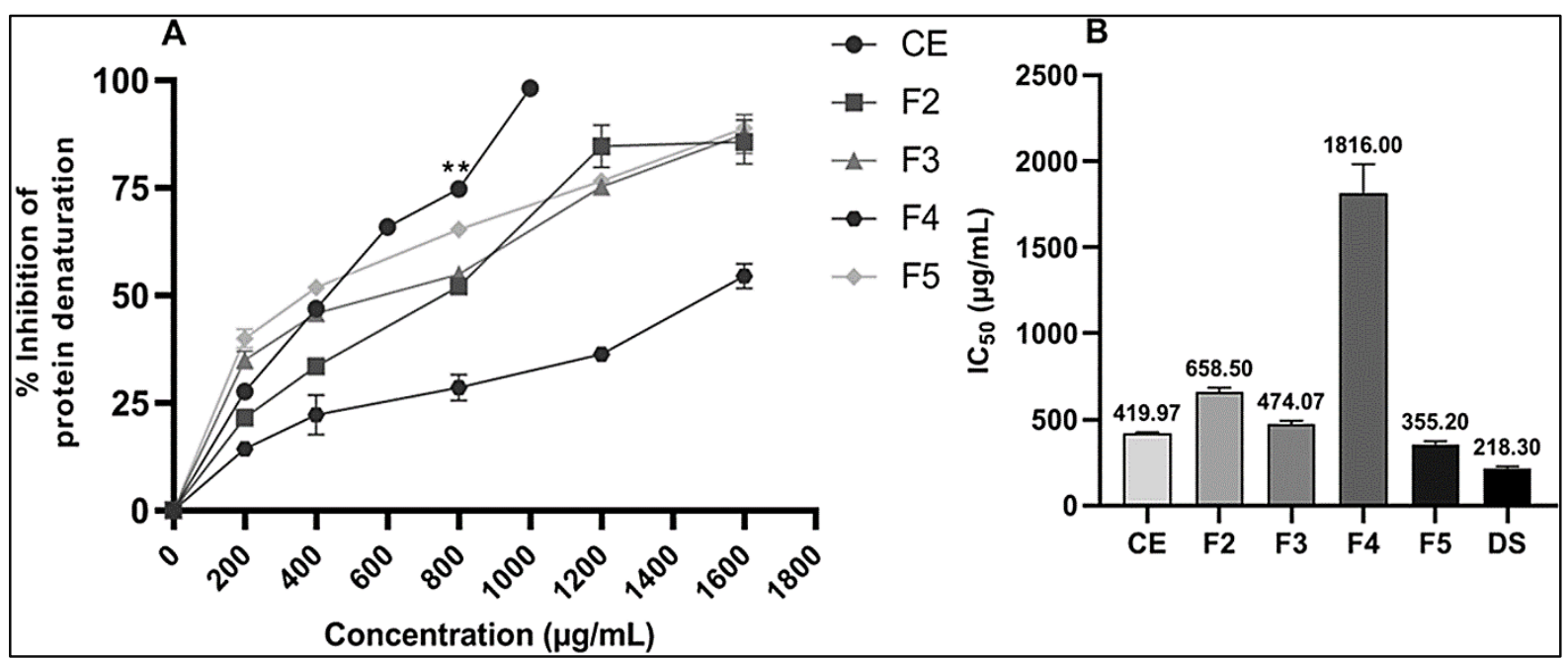

Figure 4. In vitro inhibition of protein denaturation of the crude and fractionated extracts of $M$. balbisiana fruits. DS, CE, F2, F3, F4, and F5: Diclofenac sodium, crude extract, chloroform, ethyl acetate, $n$-butanol, and aqueous fractions, respectively. (A) Percentage inhibition of protein denaturation activity: ${ }^{* *} p<0.01$ significant difference compared to F5 fraction at the same concentration; ${ }^{* * *} p<0.001$ significant difference compared to F3 and F4 fractions at the same concentration; and ${ }^{* * * *} p<0.0001$ significant difference compared to $\mathrm{F} 2$ fraction at the same concentration. (B) The $\mathrm{IC}_{50}$ values: ${ }^{a} p<0.05$ significant difference compared to other extracts, excepted F5; ${ }^{b} p<0.05$ significant difference compared to all other extracts; ${ }^{c} p<0.05$ significant difference compared to other extracts, expected CE extract and DS. Values were expressed as Mean $\pm \operatorname{SEM}(n=3)$. 
The result indicated that the maximum inhibition at a concentration of $800 \mu \mathrm{g} / \mathrm{mL}$ was the potential crude extract, compared with other extracts at the same concentration. From Figure $4 \mathrm{~B}$, the $\mathrm{IC}_{50}$ value order for against protein denaturation starting from the lower to the higher were aqueous fraction, crude extract, ethyl acetate fraction, chloroform fraction, and $n$ butanol fraction, compared with the diclofenac sodium, as a standard anti-inflammatory drug.

The percent inhibition of heat-induced hemolysis of RBCs at different concentrations from different extracts of $M$. balbisiana fruits, in the range of $31.25-500 \mu \mathrm{g} / \mathrm{mL}$, was shown in Figure 5A. The crude and fractionated extracts of $M$. balbisiana fruits were able to inhibit hemolysis in a concentration-dependent manner. Maximum inhibition $90.69 \pm 1.14 \%$ shown by the ethyl acetate fraction obtained for a concentration of $500 \mu \mathrm{g} / \mathrm{mL}$ followed by potential crude extract, aqueous, chloroform, and $n$-butanol fractions. Diclofenac sodium presented the maximum inhibition $80.08 \pm 1.46 \%$ at a concentration of $200 \mu \mathrm{g} / \mathrm{mL}$. The $\mathrm{IC}_{50}$ values from the lower to the higher for against damaging effects of heat condition were ranged ethyl acetate, crude extract, chloroform, aqueous and $n$-butanol fractions. Besides, the $\mathrm{IC}_{50}$ value for against lysis shown by positive control was significantly lower than that obtained for the value of different extracts. (Figure 5B.)

Similarly, in hypotonicity-induced hemolysis, the crude extract and fractions were effective in inhibiting the hypotonicity induced hemolysis at different concentrations $(15.63-250 \mu \mathrm{g} / \mathrm{mL})$. The inhibition of hemolysis was found to be a concentration-dependent manner. From the result shown in Figure 5C, ethyl acetate fraction also accounted maximum percentage of inhibition $90.11 \pm 0.26 \%$ at a concentration of $250 \mu \mathrm{g} / \mathrm{mL}$, followed by the crude extract, $n$-butanol, aqueous and chloroform fractions, at the same concentration, whereas, diclofenac sodium (200 $\mu \mathrm{g} / \mathrm{mL}$ ) showed $79.85 \pm 1.48 \%$ inhibition of RBCs hemolysis. Figure $5 \mathrm{D}$ indicated that the $\mathrm{IC}_{50}$ value of the ethyl acetate fraction, crude extract, $n$-butanol, aqueous and chloroform fractions for inhibited lysis induced by the hypotonic solution. Interestingly, the $\mathrm{IC}_{50}$ value for against lysis shown by the ethyl acetate fraction and crude extract were lower than those obtained for the value of diclofenac sodium. Therefore, these extracts could be considered alternatives for a standard anti-inflammatory drug during protected the RBCs against lysis induced by the hypotonic solution without side-effects.

\subsection{Antibacterial activity of crude and fractionated extracts}

In the present study, the crude extract and different fractions at various concentrations was performed to evaluate the effectiveness in antibacterial activity against Gram-negative bacteria such as E. coli, $P$. aeruginosa, and Gram-positive bacteria such as $S$. aureus. Results showed that the crude extract and its fractions possessed inhibitory activities against all tested bacteria. However, only the $n$-hexane fraction did not exhibit activity against the three tested bacterial strains. Based on the mean value zone of inhibition, the ability of the crude extract and its fractions in antibacterial activity was depending on the different concentrations. Zones of inhibition produced by the crude and fractionated extracts were demonstrated in Figure 6. The most sensitive organisms to the extracts were $E$. coli while $S$. aureus and $P$. aeruginosa was the least sensitive. Amoxicillin was used as a standard drug in this test. The concentration of amoxicillin in inhibiting bacterial activities were $E$. coli $(25 \mu \mathrm{g} / \mathrm{mL}), S$. aureus $(50 \mu \mathrm{g} / \mathrm{mL})$, and $P$. aeruginosa $(100$ $\mu \mathrm{g} / \mathrm{mL}$ ) with zone of inhibition of $28.33 \pm 1.76$, $22.67 \pm 2.02$, and $27.33 \pm 1.20(\mathrm{~mm})$, respectively.

Furthermore, the MIC and MBC of the crude extract and its fractions were summarized in Table 1. The result indicated that the potency of an antibacterial agent was an inverse measurement of its MIC and MBC. The crude extract and different fractions or drugs that had low MIC and MBC against bacteria were tested to be potent. Therefore, the extracts of $M$. balbisiana fruits could be considered alternatives for researching new herbal medicines against some microorganisms, which were resistant drugs routine.

\section{DISCUSSION}

Kidney stone disease (urolithiasis) is the foremost problem of public health for most people nowadays. Prevention and treatment are two important steps to control crystallization events. $\mathrm{CaO}_{\mathrm{x}}$ is the main constituent of kidney stones and based on supersaturation, $\mathrm{CaO}_{\mathrm{x}}$ crystals deposition inside the urinary tract. The important condition in crystallization is increased urinary supersaturation with calcium oxalate, followed by nucleation, then growth, and aggregation with other crystals in solution ${ }^{2}$. Thus, if this progression 


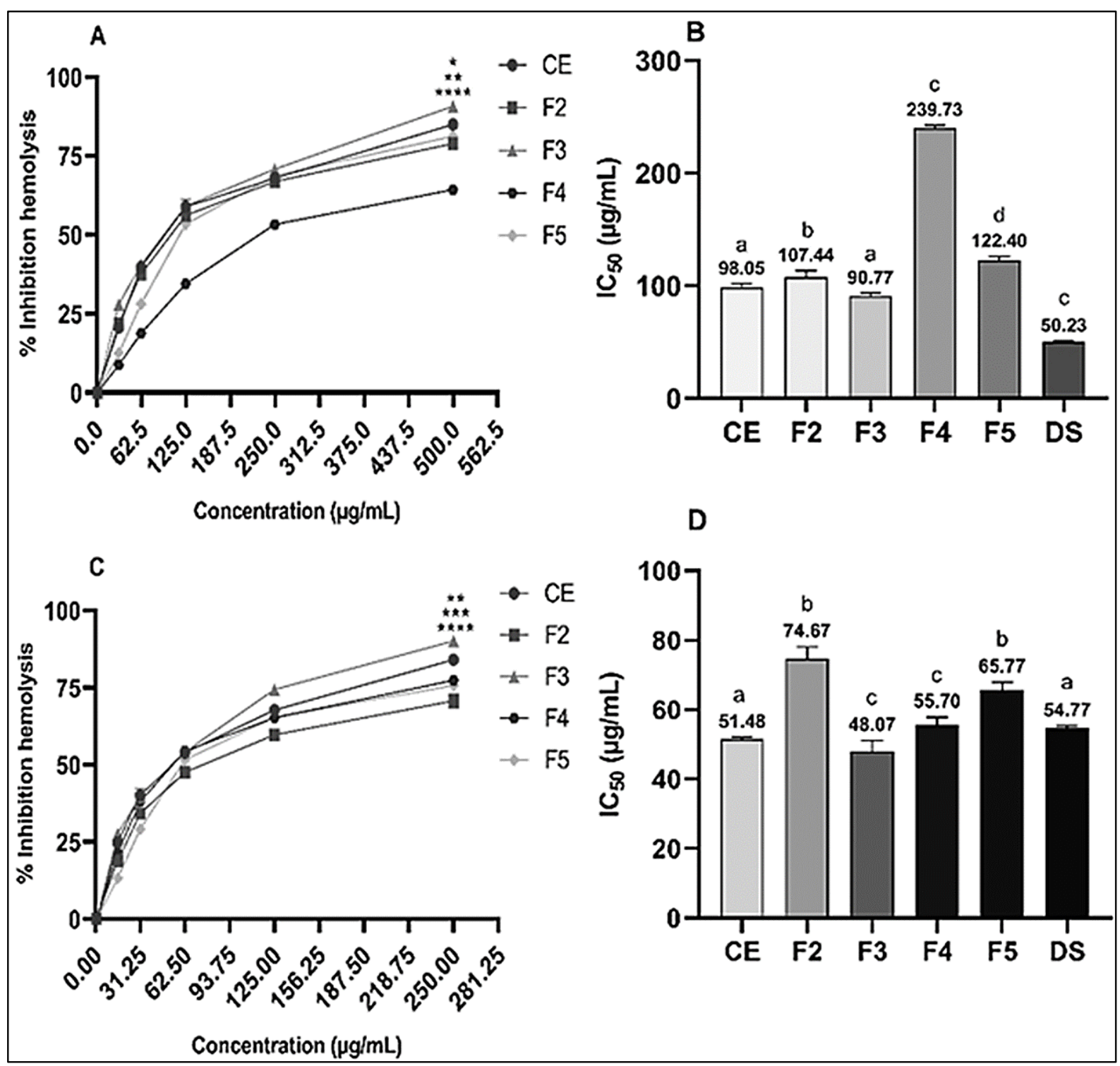

Figure 5. In vitro membrane stabilization activity of the crude and fractionated extracts of $M$. balbisiana fruits. (DS) Diclofenac sodium, (CE) crude extract, (F2) chloroform, (F3) ethyl acetate, (F4) $n$-butanol, and (F5) aqueous fractions. (A) Percentage inhibition of heat-induced hemolysis: ${ }^{*} p<0.05$ significant difference compared to CE extract; ${ }^{* *} p<0.01$ significant difference compared to F2 and F5 fractions; ${ }^{* * * *} p<0.0001$ significant difference compared to F4 fraction. (B) The IC50 values of heat-induced hemolysis: ${ }^{a} p<0.05$ significant difference compared to F4, F5 fractions and DS; ${ }^{\mathrm{b}} p<0.05$ significant difference compared to F4 fraction and DS; ${ }^{c} p<0.05$ significant difference compared to all other extracts; ${ }^{d} p<0.05$ significant difference compared to other extracts, excepted F2. (C) Percentage inhibition of hypotonicity-induced hemolysis: ${ }^{* *} p<0.01$ significant difference compared to F2 fraction; ${ }^{* * *} p<0.001$ significant difference compared to F4 fraction; ${ }^{* * * *} p<0.0001$ significant difference compared to $\mathrm{CE}$ extract and F5 fraction. (D) The $\mathrm{IC}_{50}$ values of hypotonicity-induced hemolysis: ${ }^{a} p<0.05$ significant difference compared to other extracts, excepted F3 and F4; ${ }^{b} p<0.05$ significant difference compared to CE, F3, F4, and DS; ${ }^{c} p<0.05$ significant difference compared to F2 and F5 fractions. Values were expressed as Mean $\pm \operatorname{SEM}(n=3)$.

Table 1. MIC and MBC values of the crude extract and its fractions of M. balbisiana fruits and standard antibiotic against tested microorganisms.

\begin{tabular}{ccccccc}
\hline \multirow{2}{*}{ Sample } & \multicolumn{3}{c}{ MIC $(\mathbf{m g} / \mathbf{m L})$} & \multicolumn{3}{c}{ MBC $(\mathbf{m g} / \mathbf{m L})$} \\
\cline { 2 - 7 } & E. coli & S. aureus & P. aeruginosa & E. coli & S. aureus & P. aeruginosa \\
\hline CE & 6.25 & 6.25 & 12.5 & 12.5 & 12.5 & 25 \\
F1 & ND & ND & ND & ND & ND & ND \\
F2 & 12.5 & 6.25 & 12.5 & 25 & 12.5 & 25 \\
F3 & 6.25 & 3.125 & 6.25 & 12.5 & 6.25 & 12.5 \\
F4 & 12.5 & 6.25 & 25 & 25 & 12.5 & 50 \\
F5 & 12.5 & 6.25 & 12.5 & 25 & 12.5 & 25 \\
Amoxicillin $(\boldsymbol{\mu g} / \mathbf{m L})$ & 4 & 8 & 16 & 8 & 16 & 32 \\
\hline
\end{tabular}

ND: Non-determined 


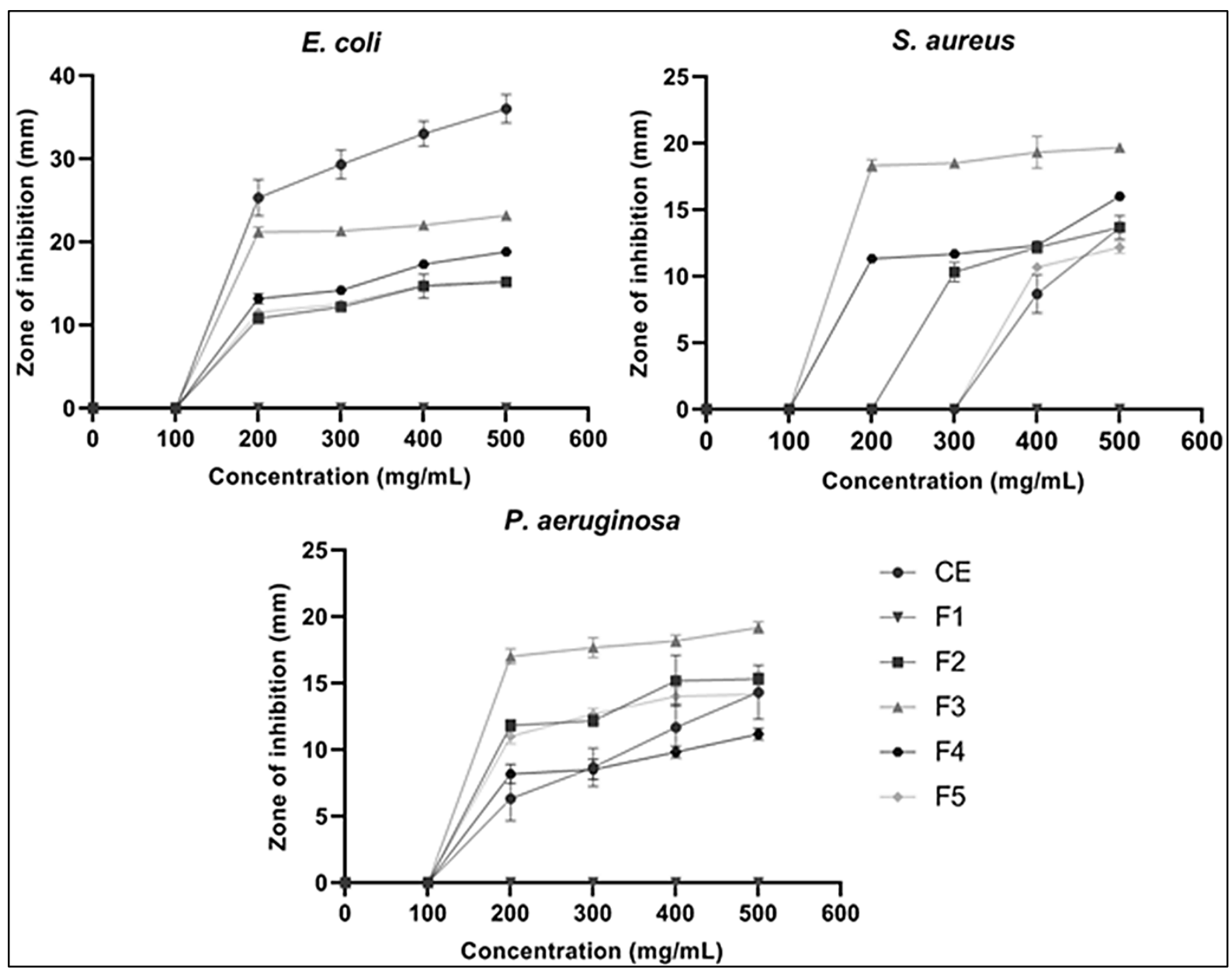

Figure 6. Zone of inhibition of the crude and fractionated extracts of $M$. balbisiana fruits and standard antibiotic against tested microorganisms. Values were expressed as Mean $\pm \operatorname{SEM}(n=3)$.

in crystallization can be prevented, then lithiasis could be avoided. This present study involved both nucleation and aggregation stages as two important stages in $\mathrm{CaO}_{\mathrm{x}}$ stones formation, following the formation of $\mathrm{CaO}_{\mathrm{x}}$ crystals in a spectrophotometer by measurement optimal density after occurring reaction between solutions of calcium chloride and sodium oxalate. The use of herbal plants could be the best source for treating and controlling kidney stone disease as these have been widely used in folk medicine to treat kidney stones, which are safe and more dependable than the costly medicines with many side effects ${ }^{13}$. The crude extract by $45 \%$ ethanol using hot extraction methods of $M$. balbisiana had shown a tremendous effect on the calcium oxalate crystal morphology, which induced change in structure, number, and size of crystals when compared with the negative control. Different types of solvents which were $n$-hexane, chloroform, ethyl acetate, $n$-butanol, and aqueous, were used to extract the bioactive compounds from the crude extract of $M$. balbisiana fruits. Our results also showed that all fractions of the crude extract presented in vitro anti-urolithic activity at different levels since the various solvents used to extract different types of constituents in herbal plant dependent on the polarity of solvents. The in vitro result given evidence for different extracts of M. balbisiana fruits which possess potent anti-urolithic ability in both nucleation and aggregation assays.

The main finding of the nucleation assay was that different extracts from $M$. balbisiana fruits promoted the $\mathrm{CaO}_{\mathrm{x}}$ crystals nucleation in a concentration-dependent manner. The crude and fractionated extracts of $M$. balbisiana fruits showed the active in the gradually reducing the size of COM crystals in solution and at its highest concentration $(1000 \mu \mathrm{g} / \mathrm{mL})$ the COM crystals were destructed and fragmented into smaller. Therefore, with the property of extract, small particles of $\mathrm{CaO}_{x}$ crystals were easily excreted from the kidney and prevented the chance of retention in the urinary tract. Whereas, aqueous fraction contained substances had similar properties of positive control, which induced a greater number and size of crystals with 
increasing concentration of extract, however, the morphology and structure of crystals were changed, the number of COM particles decreased but those of COD gradually increased, as the advantage of this property in preventing kidney stone formation. The difference in the surface structure of COM and COD crystals, COM crystals were considered to be more harmful than COD crystals because of their tendency attached to the membrane to form aggregates ${ }^{25}$. Hence, COM crystal was the reason induced the kidney stone, otherwise, COD crystal had a role in preventing kidney stones because it was easily excreted in the urine.

The main finding of the aggregation assay was that different extracts from $M$. balbisiana fruits inhibited the $\mathrm{CaO}_{\mathrm{x}}$ crystal agglomeration in a concentration-dependent manner. Crystal aggregation was a critical step in urinary stone formation, as an important process leading to crystal retentions in the urinary tract ${ }^{2}$. The crude and fractionated of M. balbisiana fruit extracts also ascertained the presence of COM crystals aggregation inhibiting constituents. The crude extract, $n$-hexane, and ethyl acetate fractions showed the maximum suppression of $\mathrm{CaO}_{\mathrm{x}}$ aggregation as compared to other fractions. Otherwise, as the above experiment, the property of these extracts could disrupt $\mathrm{CaO}_{\mathrm{x}}$ crystal aggregation. Therefore, the number of crystals increased in the solution contained extracttreated aggregation but these extracts kept $\mathrm{CaO}_{x}$ crystals disaggregation. While in the control, the crystals were strongly aggregated and increased in crystal growth. However, the data of this study could not be considered negative because these extracts also showed the potency to dissolve $\mathrm{CaO}_{\mathrm{x}}$ crystals. Dissolution potency of COM crystals by different extracts was decreased in the following order: $n$-hexane fraction $>$ crude extract $>$ ethyl acetate fraction $>n$-butanol fraction > chloroform fraction > aqueous fraction. Moreover, the present results indicated a lower $\mathrm{IC}_{50}$ value for these extracts than for sodium citrate; hence, the crude extract, $n$-hexane, and ethyl acetate fractions of $M$. balbisiana fruits showed more potency in disruption and dissolution of calcium oxalate crystals than the positive control.

Based on the results, the other reasons for different capability of $M$. balbisiana fruit extracts in anti-crystalization might be performed of the difference in solvent. Following the previous researches, $M$. balbisiana extracts showed the presence of bioactive compounds such as flavonoids, polyphenols, tannins, monoterpenoids, sesquiterpenoids, quinones, and saponins ${ }^{18}$. Saponins-rich from fruits and plants possessed anti-crystallization properties by disaggregating the suspension of mucoproteins, promoters of crystallization, growth of COM crystals ${ }^{19}$. Tannins and terpenoids helped in blocking the formation of COM particles as well as reduce precipitation of $\mathrm{CaO}_{\mathrm{x}}$ crystals ${ }^{26}$. Alkaloids contributed the beneficial activity in inhibiting the formation of calcium oxalate crystals, and preventing their attachment to renal cells ${ }^{27}$. Flavonoids also possessed $\mathrm{CaO}_{x}$ crystal dissolution potency or prevented supersaturation of calcium oxalate ${ }^{20}$. Seeing the results, the higher potency in controlling $\mathrm{CaO}_{\mathrm{x}}$ crystallization of fractions containing nonpolar, semipolar or combination both components are compared to other fractions containing hydropolar components. According to the phytochemical of M. balbisiana fruit extracts, $n$-hexane fraction had greater activity might be the presence of higher level of phytosterols and terpenoids due to its solvent was used to extract components of low polarity. Chloroform and ethyl acetate fractions were easily dissolved both medium polarities and some polar components such as alkaloids, flavonoids, tannins, and terpenoids. Saponins were well known to represent anticrystallization and anti-aggregatory properties, which was extracted by hydropolar solvents such as $n$-butanol, and aqueous fractions ${ }^{19,28}$. The effect in controlling and treating kidney stone disease in vitro would have been an outcome of these phytoconstituents present in M. balbisiana fruit extracts.

Kidney stone disease might cause kidney cell damage and inflammation due to crystal deposition inside the kidney. The antiinflammatory activity of $M$. balbisiana fruits was studied by using inhibition of protein denaturation method. Protein denaturation was a process in which protein molecules lose of biological properties. Denaturation of protein was one of the reaction in inflammation assay as had been documented ${ }^{22}$. Therefore, if protein denaturation can be prevented, then inflamematory conditions could be avoided. Similarly, the anti-inflammatory activity of $M$. balbisiana fruits was also studied by using the membrane stabilization method. Membrane proteins were especially answerable for the physical properties of the cell membrane and might support to control of the water and volume content of cells by managing the movement of sodium and potassium ions ${ }^{29}$. Since the RBCs membrane 
was similar to that of the lysosomal membrane, inhibition of RBCs hemolysis supported to understand clearly the inflammatory process ${ }^{30}$. In vitro, the effect of $M$. balbisiana fruits inhibited protein denaturation and prevented heat and hypotonicity-induced lysis of RBCs. From the result of the present study, the crude extract and fractions of $M$. balbisiana fruits, excepted $n$-hexane fraction, showed the activity in protein denaturation against egg albumin and lysis RBCs membrane. Whereas, the crude extract and ethyl acetate fraction showed to be more active in inhibiting inflammatory activity as compared to other fractions. It might be due to the higher presence of bioactivities constituents in M. balbisiana fruits. Flavonoids could help in a stabilizing membrane of lysosomes, tannin and saponin had potent in stabilizing the RBCs membrane due to its properties showed capable of binding cations ${ }^{31}$. Hence, these extracts could be used as an anti-inflammatory agent, due to potent activity and lesser side effects.

Urinary tract infections (UTI) is a serious problem caused in patients with kidney stone disease, that may as result when bacteria become trapped in urine that pools above a blockage $^{32}$. The bacterial isolates used in this study contain urinary pathogens such as $E$. coli was known to cause urinary tract infections, accounting for about $90 \%$ of cases ${ }^{9}$. From the present study, the $45 \%$ ethanol by hot extraction method was observed to possess effective activity against $E$. coli. This was attributed to the fact that $45 \%$ ethanol extracted of the bioactive component of the plant. The presence of a medicinally active compound in plants was most responsible for a vital role in antibacterial activities. Flavonoids showed the bioactive substances that have antimicrobial effects ${ }^{33}$. Tannins present in the cells of plants were potent inhibitors of many bacterial enzymes ${ }^{34}$. Saponins also had detergent properties and played an important role in disrupting the pathogen cell membranes ${ }^{35}$. From our findings, the crude extract and its fractions were found to effective against UTI bacteria $E$. coli, S. aureus, $P$. aeruginosa. The effect of the crude and fractionated extracts, and standard antibiotic in antibacterial activity were different. This might be due to bacterial structures such as differences in cell walls, the amount of peptidoglycan and the nature of cross-linking influence the bacterial activity $^{36}$. Thus, the antibacterial different activity due to the presence of the bioactive plant molecules, between Gram-negative bacteria and
Gram-positive, the plant extracts individually showed the bacteria of Gram-negative less antibacterial activities than Gram-positive bacteria.

\section{CONCLUSIONS}

The present study conclusively demonstrates that crude extract and its fractions of $M$. balbisiana fruits contribute better activity against urolithiasis, which provide scientific proof for traditional methods, which also support to scientific documentation complementary to in vitro researches. Further studies the relationship between in vitro and in vivo of $M$. balbisiana fruits may be useful to understand the mechanism of urolithiasis process as well as phytochemical constituents of the extract responsible for dissolving or disintegrating kidney stones, which are required to support the fully ethnomedicinal evidence.

\section{ACKNOWLEDGEMENTS}

The study was supported by The Youth Incubator for Science and Technology Programe, managed by Youth Development Science and Technology Center - Ho Chi Minh Communist Youth Union and Department of Science and Technology of Ho Chi Minh City, the contract number is "01/2019/HĐ-KHCN-VU"; and the Ministry of Science and Technology for the financial support under grant number NVQG2017/23.

\section{Conflict of interest}

Authors should declare their conflict of interest in this section.

\section{Funding}

None to declare.

\section{Ethics approval}

None to declare.

\section{Article info:}

Received June 15, 2020

Received in revised form July 24, 2020

Accepted November 13, 2020

\section{Authors' contributions}

H. T. Ly and V. M. Le contributed equally as co-first authors to this work.

\section{REFERENCES}

1. Finkielstein VA, Goldfarb DS. Strategies for 
preventing calcium oxalate stones. CMAJ. 2006;174: 1407-09.

2. Alelign T, Petros B. Kidney Stone Disease: An Update on Current Concepts. Adv Urol. 2018;2018:306-65.

3. Ratkalkar VN, Kleinman JG. Mechanisms of Stone Formation. Clin Rev Bone Miner Metab. 2011;9:187-97.

4. Ingale KG, Thakurdesai PA, Vyawahare NS. Effect of Hygrophila spinosa in ethylene glycol induced nephrolithiasis in rats. Indian J Pharmacol. 2012;44: $639-42$.

5. Tiwari A, Soni V, Londhe V, Bhandarkar A, Bandawane $\mathrm{D}$, Nipate $\mathrm{S}$. An overview on potent indigenous herbs for urinary tract infirmity: Urolithiasis. Asian J Pharm Clin Res. 2012;5:7-12.

6. Brikowski TH, Lotan Y, Pearle MS. Climate-related increase in the prevalence of urolithiasis in the United States. Proc Natl Acad Sci USA. 2008;105:9841-46.

7. Zanetti G, Paparella S, Trinchieri A, Prezioso D, Rocco F, Naber KG. Infections and urolithiasis: current clinical evidence in prophylaxis and antibiotic therapy. Arch Ital Urol Androl. 2008;80:5-12.

8. Srivastava J, Chandra H, Nautiyal AR, Kalra SJ. Antimicrobial resistance (AMR) and plant-derived antimicrobials (PDAms) as an alternative drug line to control infections. 3 Biotech. 2014;4:451-60.

9. Flores-Mireles AL, Walker JN, Caparon M, Hultgren SJ. Urinary tract infections: epidemiology, mechanisms of infection and treatment options. Nat Rev Microbiol. 2015;13:269-84.

10. Negus M, Phillips C, Hindley R. Recurrent urinary tract infections: a critical review of the currently available treatment options. Obstet Gynecol. 2019;22:115-21.

11. McAteer JA, Evan AP. The acute and long-term adverse effects of shock wave lithotripsy. Semin Nephrol. 2008; 28:200-13.

12. Shrestha PM, Dhillio SS. Medicinal plant diversity and use in the highlands of Dolakha district, Nepal. J Ethnopharmacol. 2003;86:81-96.

13. Bahmani $\mathrm{M}$, Baharvand-Ahmadi $\mathrm{B}$, Tajeddini $\mathrm{P}$, Rafieian-Kopaei M, Naghdi N. Identification of medicinal plants for the treatment of kidney and urinary stones. J Ren Inj Prev. 2016;5:129-33.

14. Ponnambalam H, Sellappan M. ICP-MS technique for quantification of potassium and sodium in spray-dried extract of shoot juice of banana plant (Musa balbisiana) responsible for antiurolithiatic and diuretic activity. Int J Pharm Chem Anal. 2014;4:170-74.

15. Prasobh GR, Revikumar KG. Use of Musa AAB in kidney stone treatment and other diseases. Asian J Pharm Clin Res.2011;4(3):117-18.

16. Kumar KPS, Bhowmik D, Duraivel S, Umadevi M. Traditional and Medicinal Uses of Banana. J Pharmacogn Phytochem. 2012;1(3):51-63

17. Borborah K, Borthakur SK, Tanti B. Musa balbisiana Colla-Taxonomy, traditional knowledge and economic potentialities of the plant in Assam, India. Indian J Tradit Knowl. 2016;15(1):116-20.

18. Purabi D, Ananya K, Daisy S, Chandrama B. A Review on Musa balbisiana Colla. Int J Pharm Sci Invent. 2018;7:14-7.

19. Patel PK, Patel MA, Vyas BA, Shah DR, Gandhi TR. Antiurolithiatic activity of saponin rich fraction from the fruits of Solanum xanthocarpum Schrad. \& Wendl.
(Solanaceae) against ethylene glycol induced urolithiasis in rats. J Ethnopharmacol. 2012;144:160-70.

20. Zeng X, Xi Y, Jiang W. Protective roles of flavonoids and flavonoid-rich plant extracts against urolithiasis: A review. Crit Rev Food Sci Nutr. 2019;59: 2125-35.

21. Bawari S, Sah AN, Tewari D. Antiurolithiatic Activity of Daucus carota: An in vitro Study. Pharmacogn J. 2018;10(5):880-4.

22. Gunathilake KDPP, Ranaweera KKDS, Rupasinghe HPV. In Vitro Anti-Inflammatory Properties of Selected Green Leafy Vegetables. Biomedicines. 2018;6(4):107.

23. Leelaprakash G, Mohan Dass S. In vitro antiinflammatory activity of methanol extract of Enicostemma axillare. Int J Drug Dev Res. 2011;3(3): 189-96.

24. Elisha IL, Botha FS, McGaw LJ, Eloff JN. The antibacterial activity of extracts of nine plant species with good activity against Escherichia coli against five other bacteria and cytotoxicity of extracts. BMC Complement Altern Med. 2017;17(1):133.

25. Sun XY, Xu M, Ouyang JM. Effect of crystal shape and aggregation of calcium oxalate monohydrate on cellular toxicity in renal epithelial cells. ACS Omega. 2017;2:6039-52.

26. Sharifa AA, Jamaludin J, Kiong LS, Chia LA, Osman K. Anti-urolithiatic terpenoid compound from Plantago major Linn. (Ekor Anjing). Sains Malays. 2012;41:33-9.

27. Agarwal $\mathrm{K}$, Varma R. In vitro Calcium oxalate crystallization inhibition by Achyranthes aspera $\mathrm{L}$. and Bryophyllum pinnatum Lam. J Pharm Res Int. 2014;5:146-52.

28. Noorshilawati AA, Hamimah M, Nur SA, Muhammad NO. In vitro antibacterial activity of Vernonia amygdalina leaves extracts against pathogen of pineapple heart rot disease. Gadingst. 2018;1(1):7-15.

29. Almeida DM, Oliveira MM, Saibo NJM. Regulation of $\mathrm{Na}^{+}$and $\mathrm{K}^{+}$homeostasis in plants: towards improved salt stress tolerance in crop plants. Genet Mol Biol. 2017;40:326-45.

30. Villa CH, Pan DC, Zaitsev S, Cines DB, Siegel DL, Muzykantov VR. Delivery of drugs bound to erythrocytes: new avenues for an old intravascular carrier. Ther Deliv. 2015;6:795-826.

31. Khan I, Nisar M, Ebad F, Nadeem S, Saeed M, Khan H, et al. Anti-inflammatory activities of Sieboldogenin from Smilax china Linn.: experimental and computational studies. J Ethnopharmacol. 2009;121:175-77.

32. Schwaderer AL, Wolfe AJ. The association between bacteria and urinary stones. Ann Transl Med. 2017;5:32.

33. Cushnie TP, Lamb AJ. Antimicrobial activity of flavonoids. Int J Antimicrob Agents 2005;26:343-56.

34. Buzzini P, Arapitsas P, Goretti M, Branda E, Turchetti B, Pinelli P, Ieri F, Romani A. Antimicrobial and antiviral activity of hydrolysable tannins. Mini Rev Med Chem. 2008;8:1179-87.

35. Fleck JD, Betti AH, da Silva FP, Troian EA, Olivaro C, Ferreira F, Verza SG. Saponins from Quillaja saponaria and Quillaja brasiliensis: Particular chemical characteristics and biological activities. Molecules. 2019;24(1):171.

36. Romaniuk JA, Cegelski L. Bacterial cell wall composition and the influence of antibiotics by cell-wall and whole-cell NMR. Philos Trans R Soc Lond B Biol Sci. 2015;370(11679):20150024. 